\section{Self-treatment with electricity}

DeAr SIRS

Self-medication with alcohol or illegal drugs has been frequently observed among schizophrenia sufferers. Self-treatment with electricity has not been previously described.

Mr G., a divorced, retired electrician, was admitted after being brought to casualty by his daughter. She was concerned about a number of burns on his hands and abdomen. Mr G gave an eight year history of auditory hallucinations which he believed were "good and bad spirits from the other side". He had been using a homemade device to administer electric shocks to himself, often several times a day, and explained as "driving out" spirits who were attempting to "possess" him. He believed the burns indicated sites where such spirits had been driven out. He described obtaining great but shortlived relief from the voices of the evil spirits following use of his device.

This case is an unusual example of hazardous self treatment in the setting of a psychotic illness. There was no history of self-induced convulsions, and the mechanism of symptom relief described by the patient is uncertain but likely to be due to distraction rather than any psycho-physiological effect.

Barnsley Hall Hospital

GARY HOSTY

Bromsgrove B61 OEX

\section{Submission of projects for ethical approval}

\section{DeAr SIRS}

I am writing to ask your readers whether or not they are experiencing similar problems to those we are having in North Wales, and to promote debate on possible solutions. Recently there has been an understandable and laudable 'tightening up' of the process by which research projects receive ethical approval. However, this has produced a burgeoning of bureaucratic paperwork through which the hopeful researcher must find their way.
In our hospital, which covers two health authorities, projects have to be submitted to four separate ethical approval committees, two in one health authority, one in the other, and one to the university. Each committee now has a different form on which the details of the project have to be submitted, and only one of the committees will accept word processed submissions on blank paper. This means a considerable amount of effort is required to go through all the forms, some of which are quite lengthy, answering questions which are all asked in slightly different ways. Surely a standard format or a series of headings could be recognised and used by doctors working anywhere in the country; I would be interested to know if any such system is in operation.

North Wales Hospital

G. C. HARborne

Denbigh

Clwyd LL16 5SS

\section{Appeal to libraries and individuals}

The Second World Centre has adopted the libraries of the University of Vilnius, the Russian State University of the Humanities in Moscow and the Kiev-Mogilanskaja Academy-University. It collects books, studies and journals in the English, French and German languages for all academic disciplines but with an emphasis on history, political science, languages, sociology, anthropology, psychiatry and psychology.

Many libraries and individual scholars in Europe and Northern America made donations to the project with books or financial aid for costs of transport and maintenance. Donations to some of the adopted universities have already arrived at their destination, but we would like to continue the project on a regular basis.

For more information about donations or participation in the project please contact: André Koppers, Second World Center, PO Box 3754, 1001 AN Amsterdam, The Netherlands (telephone 3120627 9491; fax 31206208116 ). 